\title{
Small Molecules that Induce Cardiomyogenesis in Embryonic Stem Cells
}

\author{
Xu Wu ${ }^{1}$, Sheng Ding ${ }^{1}$, Qiang Ding ${ }^{2}$, Nathanael S. Gray ${ }^{2}$, and Peter G. Schultz ${ }^{1,2, *}$ \\ ${ }^{1}$ Department of Chemistry and The Skaggs Institute for Chemical Biology, The Scripps \\ Research Institute, 10550 N. Torrey Pines Road, La Jolla, CA 92037 \\ ${ }^{2}$ Gnomic Institute of the Novartis Research Foundation, 10675 John Jay Hopkins Drive, \\ San Diego, CA 92121 \\ * To Whom the Correspondence should be addressed: Peter G. Schultz \\ schultz@scripps.edu
}

\section{Supporting Information}

\section{Synthesis of Cardiogenol A, B, C, and D:}

All chemicals were purchased from Aldrich. 2, 4-Dichloropurine (200 mg, 1.34 mmole) was dissolved in $5 \mathrm{~mL}$ of ethanol and $282 \mu \mathrm{L}$ (1.62 mmole) of diisopropylethylamine (DIEA) and $90 \mathrm{mg}$ (1.47 mmole) of ethanolamine were added into the solution. The reaction mixture was then heated at $50{ }^{\circ} \mathrm{C}$ for $12 \mathrm{~h}$ to afford 2-chloro-4-(1hydroxylethylamino)-pyrimidine (80\% yield). $20 \mathrm{mg}$ (0.12mmole) of 2-chloro-4-(1hydroxylethylamino)-pyrimidine was dissolved in 1-butanol $(1 \mathrm{~mL})$ and $42.4 \mathrm{mg}(0.23$ mmole) of 4-(phenylamino) aniline was added. The reaction mixture was heated at $200^{\circ} \mathrm{C}$ for $15 \mathrm{~min}$ in microwave reactor to afford cardiogenol A (85\% yield). Similarly, use of $42.7 \mathrm{mg}$ (0.23 mmole) of 4-phenoxyaniline, $28.4 \mathrm{mg}$ (0.23 mmole) of 4-methoxyaniline or $45.0 \mathrm{mg}$ (0.23 mmole) of 4-amino-trans-stilbene will afford cardiogenol B (80\% yield), C (90\% yield) or D (75\% yield), respectively. The compounds were purified by preparative HPLC using $\mathrm{H}_{2} \mathrm{O}$ (with $0.1 \%$ TFA) and MeCN as solvents with a linear 
gradient of 5\% to $90 \%$ MeCN in 10 min. The desired peaks were collected and frozendried to give final products.

Cardiogenol A: ${ }^{1} \mathrm{H}$ NMR (400MHz, DMSO): $\delta$ (ppm) 3.44 (m, 2H), 3.57 (m, 2H), 6.20 (d, 1H, J=7.2), 6.83 (t, 1H, J=7.2), 7.08 (m, 5H), 7.23 (t, 2H, J=8.3), 7.34 (d, 2H, J=7.7), 7.67 (d, 1H, J=6.6), 8.25 (s, 1H), 8.95 (s, 1H), 10.18 (s, 1H). High Resolution Mass Spectrometry (MALDI-FTMS): Calculated $\left[\mathrm{MH}^{+}\right] \quad\left(\mathrm{C}_{18} \mathrm{H}_{20} \mathrm{~N}_{5} \mathrm{O}\right)$ 322.1662, found 322.1660 .

Cardiogenol B: ${ }^{1} \mathrm{H}$ NMR (400MHz, DMSO): $\delta$ (ppm) 3.45 (m, 2H), 3.56 (m, 2H), 6.24 (d, 1H, J=7.2), 7.03 (m, 5H), 7.14 (t, 1H, J=7.4), 7.40 (t, 2H, J=7.5), 7.55 (d, 2H, J=8.6), 7.73 (d, 1H, J=7.0), 8.97 (s, 1H), 10.30 (s, 1H). High Resolution Mass Spectrometry (MALDI-FTMS): Calculated $\left[\mathrm{MH}^{+}\right]\left(\mathrm{C}_{18} \mathrm{H}_{19} \mathrm{~N}_{4} \mathrm{O}_{2}\right)$ 323.1502, found 323.1498.

Cardiogenol C: ${ }^{1} \mathrm{H}$ NMR (400MHz, DMSO): $\delta$ (ppm) 3.42 (m, 2H), 3.55(m, 2H), 3.72 (s, 3H), 6.21 (d, 1H, J=7.2), 6.97 (d, 2H, J=8.9), 7.41 (d, 2H, J=8.4), 7.66 (d, 1H, J=7.1), 8.93 (s, 1H), 10.07 (s, 1H). High Resolution Mass Spectrometry (MALDI-FTMS): Calculated $\left[\mathrm{MH}^{+}\right]\left(\mathrm{C}_{13} \mathrm{H}_{17} \mathrm{~N}_{4} \mathrm{O}_{2}\right)$ 261.1346, found 261.1342.

Cardiogenol D: ${ }^{1} \mathrm{H}$ NMR (400MHz, DMSO): $\delta$ (ppm) 3.48 (m, 2H), 3.62 (m, 2H), 6.26 (d, 1H, J=7.2), 7.27 (m, 3H), 7.38 (t, 2H, J=7.5), 7.61 (m, 6H), 7.77 (d, 1H, J=7.0), 9.00 (s, 1H), 10.35 (s, 1H). High Resolution Mass Spectrometry (MALDI-FTMS): Calculated $\left[\mathrm{MH}^{+}\right]\left(\mathrm{C}_{20} \mathrm{H}_{21} \mathrm{~N}_{4} \mathrm{O}\right) 333.1710$, found 333.1711.

\section{Cell culture and high through-put screening}

P19 cells (from ATCC) were cultured in MEM-alpha with 7.5\% new born calf serum and 2.5\% FBS (Gibco) at $37^{\circ} \mathrm{C}$ in 5\% $\mathrm{CO}_{2}$. P19CL6 cells (a gift from Dr. Michael Schneider 
and Dr. Nakamura Teruya) were cultured in MEM-alpha with 10\% FBS (from Gibco) at $37{ }^{\circ} \mathrm{C}$ in $5 \% \mathrm{CO}_{2}$. A fragment ( $\left.700 \mathrm{bps}\right)$ containing rat ANF promoter region was amplified by using PCR primers (5'-CCGACGCGTGAAACATCACATTGGTTGCCTT and 5'- CCGCTCGAGCACTCTCTGGTTTCTCTCTC) and then subcloned into the PGL3-BV luciferase reporter plasmid using MluI and XhoI restriction sites. A stable clone containing this reporter plasmid was selected and used for screening. $10^{3}$ Cells were plated in each well of 384-well plates with $100 \mu \mathrm{L}$ induction medium (MEM-alpha with $5 \%$ FBS); $500 \mathrm{~nL}$ of $1 \mathrm{mM}$ compound solution was then added into each well. After compound treatment for 3 days, the medium was changed with no additional compounds added. The luciferase activity was measured after 7 days of compound treatment using the Bright-Glo luciferase assay kit (Promega). The embryonic stem cell line R1 (a gift from Mary Andahazy at GNF) was cultured in gelatin-coated tissue culture dishes with Knockout DMEM with 15\% ES serum replacement, 1mM L-glutamine (from Gibco), 1\% nonessential amino acids stock, $1 \%$ nucleosides stock, $0.1 \mathrm{mM}$ beta-mercaptomethanol (from Specialty Media) and 1000 units/mL of leukemia inhibitory factor (LIF, from Chemicon). For differentiation, R1 cells were plated at a density of 10000 cells/well in gelatin-coated 384-well plates with $100 \mu \mathrm{L}$ of DMEM with 10\% FBS. After 3 days in the presence of compound, the medium was changed with no additional compound added and cells were cultured for another 4 days.

\section{Immunostaining of cardiac muscle markers}

Cells were fixed with $4 \%$ paraformaldehyde (Sigma) for 20 min. Cell staining was performed in PBS (Gibco) with $0.3 \%$ Triton X-100 and 6\% horse serum. Primary 
antibodies were used at the following dilutions: myosin heavy chain (MHC) mouse monoclonal antibody MF20 (Developmental Studies Hybridoma Bank, 1:200), rabbit polyclonal anti-GATA-4 antibody (Santa Cruz Biotech, 1:300), rabbit anti-MEF2 antibody (Santa Cruz Biotech, 1:100) and goat anti-Nkx2.5 antibody (Santa Cruz Biotech, 1:100). Secondary antibodies were Cy2-conjugated anti-mouse (1:300), or Cy3conjugated anti-rabbit or anti-goat antibodies (Jackson ImmunoResearch, 1:500). Cell nuclei were stained with DAPI (Roche). Images were taken with a Nikon Eclipes TE2000 microscope with 200-fold magnification. Double or triple-labeled images were assembled in Metamorph.

Supporting Figure 1: Immunostaining of ESCs without cardiogenol C treatment (control). (A). MHC (green) and Nuclei (Blue). (B). GATA-4 (Red) and Nuclei (Blue).
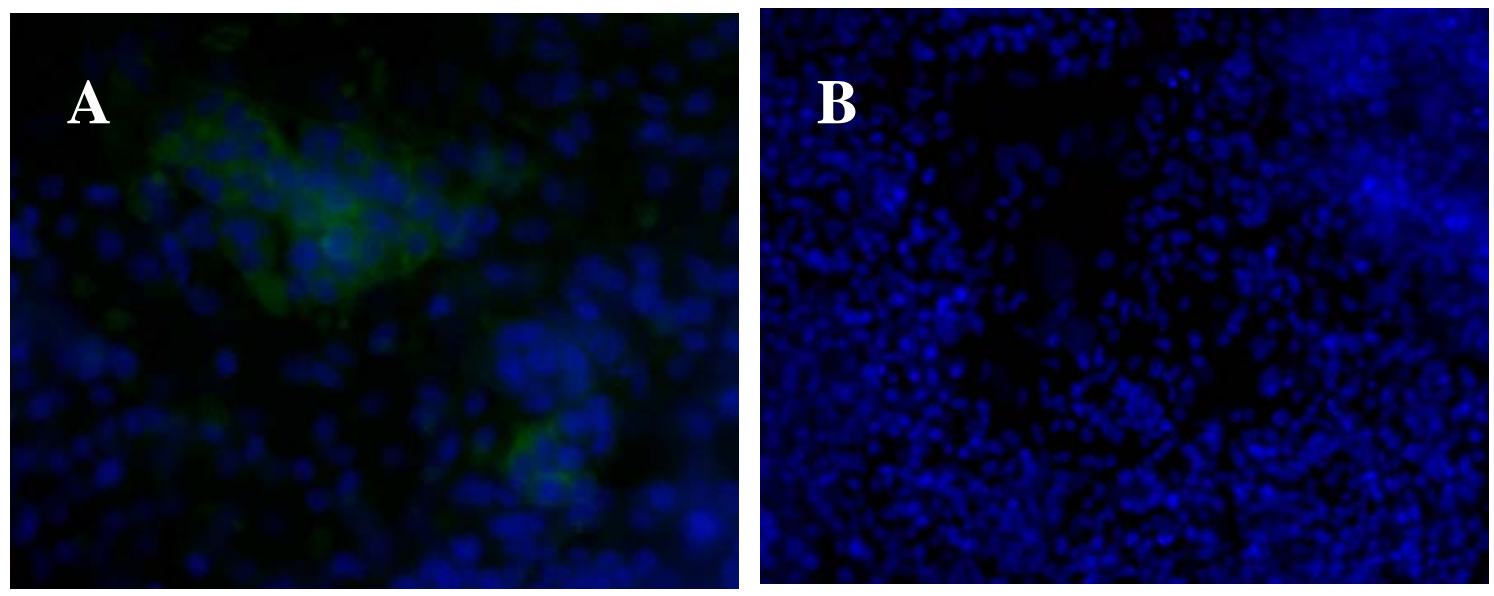